\title{
NICOLE BINGEN, Jean-Pierre de Mesmes: à propos de deux contributions récentes
}

\section{Filippo Fonio}

\section{OpenEdition}

\section{Journals}

\section{Edizione digitale}

URL: http://journals.openedition.org/studifrancesi/32996

DOI: 10.4000/studifrancesi.32996

ISSN: 2427-5856

\section{Editore}

Rosenberg \& Sellier

\section{Edizione cartacea}

Data di pubblicazione: 1 décembre 2005

Paginazione: 626

ISSN: 0039-2944

\section{Notizia bibliografica digitale}

Filippo Fonio, «NICOLE BINGEN, Jean-Pierre de Mesmes: à propos de deux contributions récentes», Studi Francesi [Online], 147 (XLX | III) | 2005, online dal 01 novembre 2015, consultato il 18 avril 2021. URL: http://journals.openedition.org/studifrancesi/32996 ; DOI: https://doi.org/10.4000/studifrancesi. 32996

Questo documento è stato generato automaticamente il 18 avril 2021.

\section{(c) (i) (9)}

Studi Francesi è distribuita con Licenza Creative Commons Attribuzione - Non commerciale - Non opere derivate 4.0 Internazionale. 


\title{
NICOLE BINGEN, Jean-Pierre de Mesmes: à propos de deux contributions récentes
}

\author{
Filippo Fonio
}

\section{NOTIZIA}

NICOLE BINGEN, Jean-Pierre de Mesmes: à propos de deux contributions récentes, «Bibliothèque d'Humanisme et Renaissance», LXVI, 2 (2004), pp. 331-357.

1 Un certo interesse per la figura e l'opera di Jean-Pierre de Mesmes negli ultimi anni è testimoniato dall'edizione, a cura di Giada Mattarucco, della Grammaire italienne composée en françois, con traduzione italiana e commento, e dallo studio di Catherine Magnien sull'Epithalame de Henry de Mesmes et de Jane Hennequin, modello per un'ode di Du Bellay. Nicole Bingen, a margine di tali recenti contributi, precisa alcune questioni inerenti la vita e l'attività di Jean-Pierre de Mesmes. La studiosa mostra fra l'altro che la tesi vulgata a partire da La Croix du Maine nel 1584, secondo la quale Jean-Pierre sarebbe un figlio naturale di Jean-Jacques de Mesmes, è insostenibile per ragioni cronologiche. Altre circostanze in merito alle quali il presente contributo fornisce nuovi elementi sono: l'epoca dell'arrivo e della partenza di Jean-Pierre de Mesmes da Parigi; il probabile viaggio in Italia compiuto all'epoca della compilazione della Grammaire; alcune precisazioni in merito alle fasi successive della sua attività, di italianista, poeta in lingua francese legato al milieu della Pléiade e divulgatore di conoscenze scientifiche, astronomiche in particolare; la possibile attribuzione di una lirica italiana contenuta nel tombeau di Henri II. 